\title{
Porto-Sinusoidal Vascular Disease with Obliterative Portal Venopathy Associated with Long-Term Azathioprine for Crohn's Disease
}

Richard A. Manfready ${ }^{1,2}$, Jack Husney ${ }^{1}$, Swan Thung ${ }^{3}$, Ilan S. Weisberg ${ }^{1, *}$

1. Department of Gastroenterology, Mount Sinai Beth Israel, New York, NY; E-Mails: richard_a_manfready@rush.edu; jack.husney@mountsinai.org; ilan.weisberg@mountsinai.org

2. Division of Digestive Diseases, Rush University Medical Center, Chicago, IL

3. Department of Pathology, Mount Sinai Hospital, New York, NY; E-Mail: swan.thung@mountsinai.org

* Correspondence: Ilan S. Weisberg; E-Mail: ilan.weisberg@mountsinai.org

Academic Editor: Tatsuo Kanda

OBM Hepatology and Gastroenterology

2020, volume 4, issue 3

doi:10.21926/obm.hg.2003051
Received: March 04, 2020

Accepted: September 17, 2020

Published: September 25, 2020

\begin{abstract}
Patients receiving immunosuppressive therapy for inflammatory bowel disease may be susceptible to non-cirrhotic portal hypertension, now referred to as porto-sinusoidal vascular disease. Here we describe a patient treated with long-term azathioprine for Crohn's disease who developed porto-sinusoidal vascular disease with obliterative portal venopathy without nodular regenerative hyperplasia on histology. Specific signs of portal hypertension were present, including porto-systemic collaterals on imaging. Histopathologic findings of porto-sinusoidal vascular disease support the hypothesis of endothelial cell injury induced by 6-thioguanine secondary to azathioprine use.
\end{abstract}

\section{Keywords}

Porto-sinusoidal vascular disease, obliterative portal venopathy, azathioprine, Crohn's disease

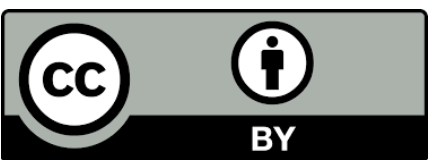

(C) 2020 by the author. This is an open access article distributed under the conditions of the Creative Commons by Attribution License, which permits unrestricted use, distribution, and reproduction in any medium or format, provided the original work is correctly cited. 


\section{Introduction}

Porto-sinusoidal vascular disease (PSVD), formerly known as idiopathic non-cirrhotic portal hypertension, is caused by a heterogeneous group of intrahepatic and extrahepatic etiologies [1]. PSVD is characterized by portal hypertension, the absence of cirrhosis as documented histologically in an appropriate liver specimen, the absence of obstruction of the extrahepatic portal vein or hepatic venous outflow tract, and the absence of sarcoidosis, schistosomiasis, congenital hepatic fibrosis, or other causes of cirrhosis [2]. Like cirrhosis, PSVD typically presents with signs of portal hypertension, especially variceal bleeding and splenomegaly [3], and is associated with poor survival [4].

In rare cases, immunosuppressive drugs, particularly azathioprine [5-6], 6-mercaptopurine [7-8], and 6-thioguanine (6-TG) [9], have been implicated in nodular regenerative hyperplasia (NRH), a form of PSVD [10]. The largest case series to date documented 37 cases of NRH in patients with inflammatory bowel disease treated with a median azathioprine dose of $2 \mathrm{mg} / \mathrm{kg} / \mathrm{day}$; five-year cumulative risk was $0.5 \%$ (95\% confidence interval $0.11-0.89)$ [5]. One case study of azathioprine used in a patient with ulcerative colitis documented the occurrence of $\mathrm{NRH}$, veno-occlusive disease, and hepatocellular carcinoma [11].

While the pathogenesis of azathioprine-induced PSVD remains uncertain, there is evidence from murine models to suggest that glutathione depletion is toxic to sinusoidal endothelial cells, leading to veno-occlusive disease on histology [12]. Accordingly, it has been shown that renal transplant recipients on azathioprine may undergo non-thrombotic obliteration of central or sublobular hepatic veins, resulting in severe portal hypertension [13]. Venous obliteration is thought to be a consequence of damage to endothelial cells lining the sinusoids and terminal hepatic venules, a process that almost exclusively affects male patients [14]. Here, we augment this literature by describing a case of PSVD with obliteration of small portal vein branches on histology but with patent vessels on imaging, in a Crohn's disease patient treated with azathioprine for 20 years.

\section{Case Report}

Our patient, a 44 year-old man with a history of insulin-dependent diabetes mellitus was diagnosed at age 19 with Crohn's Disease confined to the terminal ileum, managed with azathioprine at an average maintenance dose of $1 \mathrm{mg} / \mathrm{kg} / \mathrm{day}$. Intermittent Crohn's flares were treated with prednisone. Small bowel resection ( $8 \mathrm{~cm}$ of terminal ileum) was performed at age 35 .

Esophagogastroduodenoscopy at age 40 showed four columns of grade II esophageal varices. Ultrasonography revealed increased liver echogenicity and marked heterogeneity, as well as portal vein dilatation and splenomegaly (Figure 1). The patient was put on beta-blocker therapy. Azathioprine was discontinued after about 20 years of treatment and adalimumab was started. At age 41, the patient developed coccidioidomycosis; adalimumab was discontinued and vedolizumab was started.

Magnetic resonance cholangiography with intravenous contrast at age 44 was remarkable for splenomegaly, splenic varices, and splenorenal shunt. The liver appeared non-dysmorphic and noncirrhotic, portal veins were patent, and there was no evidence of primary sclerosing cholangitis (PSC). Laboratory studies were significant for thrombocytopenia (PIt $79 \times 10^{3} / \mathrm{uL}$ ), leukopenia 
(WBC $2.2 \times 10^{3} / \mathrm{uL}$ ), and microcytic anemia (Hgb $10.8 \mathrm{~g} / \mathrm{dL}, \mathrm{HCT} 34.2 \%$, MCV 66.8 FL, RDW 18.7\%). The patient did not carry known gene mutations conferring thiopurine methyltransferase deficiency [15]. There were no presenting symptoms or laboratory abnormalities to suggest ascites or cholestasis. (Cr 0.76 mg/dL, Alk Phos 116 U/L, AST 29 U/L, ALT 27 U/L, and Bili Total 1.3 $\mathrm{mg} / \mathrm{dL}$.)

Ultrasound-guided liver biopsy specimen was analyzed with hematoxylin, eosin, trichrome and reticulin stains. The specimen consisted of 3 cores measuring $1.4-1.6 \mathrm{~cm}$ in length and $0.1 \mathrm{~cm}$ in diameter and contained 10 complete portal tracts. Histology showed no cirrhosis. All small portal tracts were fibrotic and devoid of portal venules, indicative of obliterative portal venopathy. "Herniated" portal venules (outlet venule dilatation) were present (Figure 2). Periportal hepatocytes contained few glycogenated nuclei. There were no signs of alcoholic or nonalcoholic fatty liver disease. Hyperplasia of hepatocytes, which may develop in response to obliterative portal venopathy and would suggest $\mathrm{NRH}$, was not present as confirmed by the reticulin stain [10]. There was no evidence of bridging or sinusoidal fibrosis on trichrome stain.

The patient was managed on beta-blocker therapy for esophageal varices and lactulose with rifaximin for signs of hepatic encephalopathy. Given the findings of intrahepatic damage and Model for End-Stage Liver Disease [16] score of 12, liver transplantation was considered. Crohn's disease was well-managed with vedolizumab.
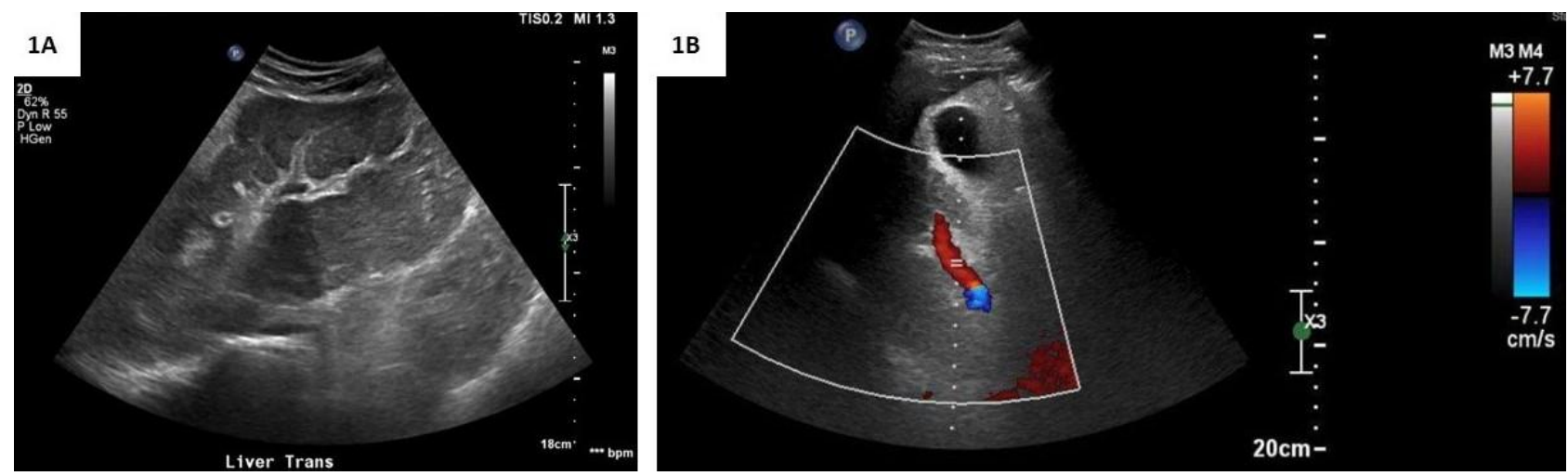

Figure 1 Liver ultrasonography demonstrated increased echogenicity and heterogeneity. The portal vein was dilated and demonstrated hepatofugal flow, representing portal hypertension. 

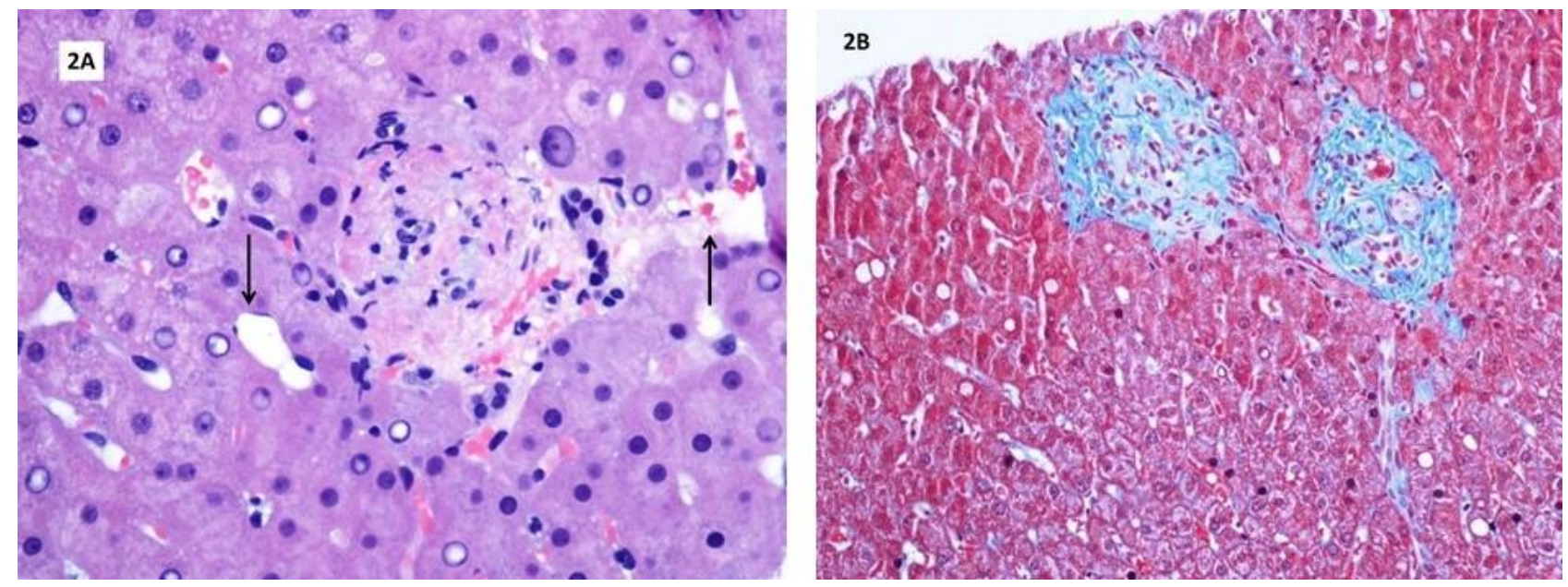

Figure 2 Absence of portal veins from portal tracts with dilatations of the outlet venules ("herniated" portal veins, arrows), consistent with obliterative portal venopathy (a. H\&E stain $\times 200$; b. Trichrome stain $\times 100$ ).

\section{Discussion}

Long-term use of azathioprine as a steroid-sparing agent in our patient with Crohn's disease likely contributed to PSVD presenting with esophageal varices, splenomegaly, and thrombocytopenia. There was no evidence for clinical, radiological, or histological cirrhosis, fatty liver disease, PSC, or small duct PSC. Portal fibrosis and obliterative venopathy on histology in the absence of vascular occlusion on imaging suggest that portal hypertension in our patient was heralded by intrahepatic changes. Damage to endothelium by long-term use of 6-TG represents one possible mechanism after exclusion of classically associated conditions such as altered immunity and thrombophilia.

Our case applies the model of azathioprine-induced vascular injury to portal vein branches. Histology demonstrated the absence of NRH. However, obliterative portal venopathy accompanying NRH has been described and can be easily missed on needle biopsy [17]. Obliterative vasculopathy of the small portal vein branches may be a key feature of PSVD histopathology. In one series of PSVD, venous branches were completely obliterated by fibrosis and hepatic architecture was remodeled with areas of nodular hyperplasia alternating with atrophic areas [18]. Another series noted phlebosclerosis and portal tract remnants as hallmark features [19]. Azathioprine exposure may lead to zone 3 circulatory disturbances causing sinusoidal obstruction; we show here that obliterative portal venopathy may be part of azathioprine toxicity as well.

PSVD following long-term azathioprine may be a rare occurrence. Suárez-Ferrer, et al. report four cases of idiopathic portal hypertension among 927 inflammatory bowel disease patients treated with thiopurine drugs. They noted that thrombocytopenia may be the earliest pre-clinical predictor of disease [20].

Despite supporting clinical evidence, our mechanistic conclusions have several limitations. Whether occlusive venopathy is attributable to 6-TG toxicity alone remains unclear. There is evidence from myasthenia gravis (MG) case reports that MG patients on azathioprine [21] and MG patients not on azathioprine are both prone to PSVD, with the implication that immunologic 
mechanisms intrinsic to MG may have contributed to the pathogenesis in the latter case [16]. Likewise, inherent immune dysfunction in our patient with Crohn's disease [22] may have played a role in the absence of immunosuppressive therapy [1]. Additionally, portal hypertension in our patient is unlikely to be attributable to PSC; a small percentage (3.3\%) of patients in one PSC transplant study had portal hypertension without cirrhosis due to $\mathrm{NRH}$ or obliterative venopathy [23].

\section{Conclusions}

Porto-sinusoidal vascular disease, confirmed on histology, should be considered as a rare complication of long-term azathioprine therapy. Further inquiry should continue to address the safety of immunosuppressive drugs in patients with Crohn's disease, as well as evaluate the potential for PSVD reversal [24-25] upon immunotherapy discontinuation.

\section{Author Contributions}

R.A.M. and J.H. analyzed, prepared, and drafted the case study. S.T. performed pathology studies and prepared images, and I.S.W. managed the patient and edited this work. All authors edited and approved the final version of the manuscript.

\section{Funding}

Funding was provided by the Mount Sinai Beth Israel Department of Internal Medicine.

\section{Competing Interests}

The authors have declared that no competing interests exist.

\section{References}

1. Schouten JNL, Verheij J, Seijo S. Idiopathic non-cirrhotic portal hypertension: A review. Orphanet J Rare Dis. 2015; 10: 67.

2. De Gottardi A, Rautou PE, Schouten J, et al. Porto-sinusoidal vascular disease: Proposal and description of a novel entity. Lancet Gastroenterol Hepatol. 2019; 4: 399-411.

3. Schouten JN, Garcia-Pagan JC, Valla DC, et al. Idiopathic noncirrhotic portal hypertension. Hepatology. 2011; 54: 1071-1081.

4. Schouten JNL, Nevens F, Hansen B, et al. Idiopathic noncirrhotic portal hypertension is associated with poor survival: Results of a long-term cohort study. Aliment Pharmacol Ther. 2012; 35: 1424-1433.

5. Vernier-Massouille G, Cosnes J, Lemann M, et al. Nodular regenerative hyperplasia in patients with inflammatory bowel disease treated with azathioprine. Gut. 2007; 56: 1404-1409.

6. Daniel F, Cadranel JF, Seksik P, et al. Azathioprine induced nodular regenerative hyperplasia in IBD patients. Gastroenterol Clin Biol. 2005; 29: 600-603.

7. De Boer NKH, Tuynman H, Bloemena E, et al. Histopathology of liver biopsies from a thiopurine-naïve inflammatory bowel disease cohort: Prevalence of nodular regenerative hyperplasia. Scand J Gastroenterol. 2008; 43: 604-608. 
8. Calabrese E, Hanauer SB. Assessment of non-cirrhotic portal hypertension associated with thiopurine therapy in inflammatory bowel disease. J Crohns Colitis. 2011; 5: 48-53.

9. Dubinsky MC, Vasiliauskas EA, Singh $\mathrm{H}$, et al. 6-Thioguanine can cause serious liver injury in inflammatory bowel disease patients. Gastroenterology. 2003; 125: 298-303.

10. Wanless IR, Godwin TA, Allen F, Feder A. Nodular regenerative hyperplasia of the liver in hematologic disorders: a possible response to obliterative portal venopathy. A morphometric study of nine cases with an hypothesis on the pathogenesis. Medicine (Baltimore). 1980; 59: 367-379.

11. Russmann S, Zimmermann A, Kra S, et al. Veno-occlusive disease, nodular regenerative hyperplasia and hepatocellular carcinoma after azathioprine treatment in a patient with ulcerative colitis. Eur J Gastroenterol Hepatol. 2001; 13: 287-290.

12. DeLeve LD, Wang $\mathrm{X}$, Kuhlenkamp JF, et al. Toxicity of azathioprine and monocrotaline in murine sinusoidal endothelial cells and hepatocytes: The role of glutathione and relevance to hepatic venoocclusive disease. Hepatology. 1996; 23: 589-599.

13. Read $A E$, Wiesner $R H$, LaBrecque $D R$, et al. Hepatic veno-occlusive disease associated with renal transplantation and azathioprine therapy. Ann Intern Med. 1986; 104: 651-655.

14. Haboubi NY, Ali HH, Whitwell HL, et al. Role of endothelial cell injury in the spectrum of azathioprine-induced liver disease after renal transplant: Light microscopy and ultrastructural observations. Am J Gastroenterol. 1988; 83: 256-261.

15. Yates CR, Krynetski EY, Loennechen T, et al. Molecular diagnosis of thiopurine Smethyltransferase deficiency: Genetic basis for azathioprine and mercaptopurine intolerance. Ann Intern Med. 1997; 126: 608-614.

16. Kamath PS, Wiesner RH, Malinchoc $\mathrm{M}$, et al. A model to predict survival in patients with endstage liver disease. Hepatology. 2001; 33: 464-470.

17. Agrawal M, Rahmani R, Nakkala K, Fiel MI, et al. Hepatoportal sclerosis (obliterative portal venopathy) and nodular regenerative hyperplasia in a patient with myasthenia gravis: A case report and review of the published work. Hepatol Res. 2013; 43: 999-1003.

18. Ibarrola C, Colina F. Clinicopathological features of nine cases of non-cirrhotic portal hypertension: Current definitions and criteria are inadequate. Histopathology. 2003; 42: 251264.

19. Verheij J, Schouten JNL, Komuta $M$, et al. Histological features in western patients with idiopathic non-cirrhotic portal hypertension. Histopathology. 2013; 62: 1083-1091.

20. Suárez-Ferrer C, Llop-Herrera E, Calvo-Moya M, et al. Idiopathic portal hypertension regarding thiopurine treatment in patients with inflammatory bowel disease. Rev Esp Enferm Dig. 2016; 108: 79-83.

21. Fonseca V, Havard CW. Portal hypertension secondary to azathioprine in myasthenia gravis. Postgr Med J. 1988; 64: 950-952.

22. Manfready RA, Husney J, Golfeyz S, et al. Long-term azathioprine use and the development of non-cirrhotic portal hypertension. Am J Gastroenterol. 2018; 113: S1275.

23. Lindor KD, Kowdley KV, and Harrison ME. ACG clinical practice guideline: Primary sclerosing cholangitis. Am J Gastroentrol. 2015; 110: 646-659.

24. Seiderer J, Zech CJ, Diebold J, et al. Nodular regenerative hyperplasia: A reversible entity associated with azathioprine therapy. Eur J Gastroenterol Hepatol. 2006; 18: 553-555. 
25. Simsek $M$, Meijer $B$, Ramsoekh $D$, et al. Clinical course of nodular regenerative hyperplasia in thiopurine treated inflammatory bowel disease patients. Clin Gastroenterol Hepatol. 2019; 17: 568-570.

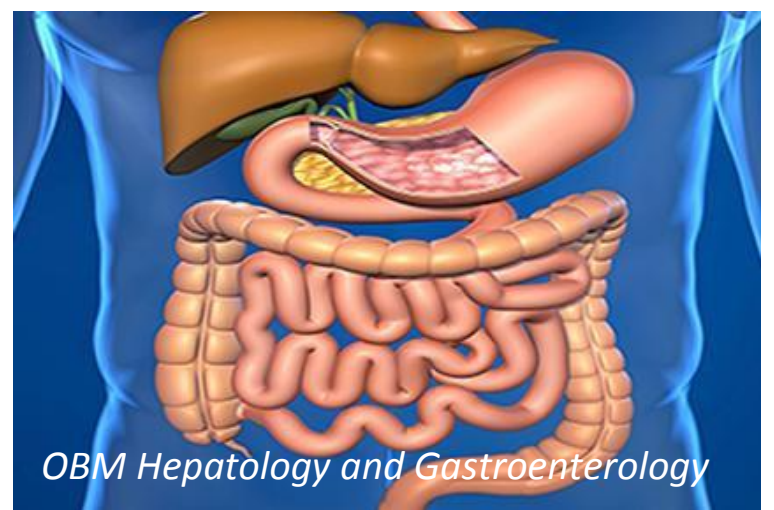

Enjoy OBM Hepatology and Gastroenterology by:

1. Submitting a manuscript

2. Joining in volunteer reviewer bank

3. Joining Editorial Board

4. Guest editing a special issue

For more details, please visit: http://www.lidsen.com/journals/hg 